\title{
Prohibición de los Comentarios Reales
}

\author{
POR: Daniel VAlcárcel
}

Los Comentarios Reales del insigne mestizo cusqueño Garcilaso Chimpuocllo, es libro imprescindible para el conocimiento de la historia cultural incaica y básico monumento espiritual de la peruanidad. Ya afianzado el virreinato hispánico, grupos selectos de indios y mestizos fortalecían su espíritu con la lectura de aquel libro y cultivaban un promisor espíritu de rebeldía, que florece indiscutible durante la época borbónica. Puede afirmarse plenamente que el mensaje constructivo de peruanísima reivindicación yacente en los Comentarios Reales, juega papel fundamental en la persistencia del Perú incaico, tanto como añoranza durante el Perú colonial, cuanto como incitactón $a$ vivir desdo y cor el país en el Perú independiente. "Jorge Puccinelli Converso"

Uno de los tantos matices que enriquecen aún más la clásica obra de Garcilaso Chimpuocllo, está representado por su influencia on la precursora rebelión social y política que encabezó el cacique de Pampamarca, Tungasuca y Surimana, José Gabriel Túpac Amaru. Aunque la prohibición de los Comentarios Reales en 1782, es consecuencia de indagaciones judiciales originadas por la rebelión de 1780, hubo ya prohibición anterior representada por las Reales Cédulas de 11-IV-1729 y 28-X-1741, cuyos textos asocian los nombres de Garcilaso Chimpuocllo y Hernán Cortes.

En los documentos judiciales acerca de personas comprometidas en la rebelión de Túpac Amaru, aparecen declaraciones de varios cusqueños manifestando ser asiduos lectores de los Comentarios y haberse reunido en Lima para conspirar. Túpac Amaru al viajar a Lima, renovaría aquellas lecturas con sus antiguos amigos. Los contertulios son personajes importantes y aparecen, 
especialmente, en el Testimonio de los autos seguidos contra Mariano Isidoro de la Barreda "por confidente" de Túpac Amaru. Hay que recordar con particular atención las declaraciones de Miguel Montiel, nacido en el pueblo de Oropesa - provincia de Quispicanchis-, personaje que estuvo $\in$ n España, Francia e Inglaterra. Montiel conoció y trató a Túpac Âmaru entre 1777 y 1778, de cuya persona tuvo "un alto consepto". Parece haber sido individuo de buena posición económica y hábil comerciante. Aparece prestando la respetable cantidad de 8,000 pesos a Túpac Amaru. Su relación con éste debió ser bastante estrecha. Se trataba de "primo" con A.lexo Túpac Amaru, residente en Lima, primo hermano del caudillo cusqueño. En declaraciones hechas por Montiel en diciembre do 1780, al ser preguntado acerca de sus aficiones intelectuales respondió que solía "leer Libros místicos, y algunos de Historia y entre estos los Comentarios de los Yngas por Garcilaso", cuyo texto comentaba con sus vecinos el comerciante Manuel de la Torre y Fernando Vila. La declaración está ratificada por el primero. El testigo José Bustinsa señaló, asimismo, al comerciante Montiel como asiduo lector de los Comentarios Reales, declaración que ratifica Francisco Fernández de Olea. La lectura y glosa en común se acompañó muchas veces con el préstamo intermitante del citado libro. ${ }^{1}$.

Pocos días hacía que Túpác Almaru había sido derrotado y capturado cuando, el 10-IV-1781, el visitador José Antonio de Areche -enviado a combatir la rebelión con el mariscal de campo José del Valle y Torres- mandó una comunicación al obispo críollo Juan Manuel de Moscoso y Peralta -célebre eclesiástico arequipeño- destinada a borrar el recuerdo de las pasadas grandezas incaicas. El Visitador pedía al Obispo -en servicio del Reyordenase sacar "del puesto en que se halla en el Colegio de San Francisco de Borja ${ }^{2}$ de esta ciudad el Quadro, ó Lienzo en que se representa la subcesion de los Yngas con sus trages, tomando un qualquiera pretexto que no descubra el fin que deve tener" 3 . Pe-

A.G.I., Audiencia de Lima, Legajo 1049.

Academia de la Historia de Madrid, Colección Matalinares, tomo 57.

2 Este Colegio se conoció también como el Colegio de Caciques.

3 A.G.I., Audiencia del Cusco, Legajo 29.

Véase del suscrito Documentos de la Audiencia del Cusco en el A.G.I. Lima, Edit. San Marcos, 1957. 
día el Visitador que igual cosa se realizase con otro cuadro semejante que existía en la iglesia del pueblo de Curawasi.

El obispo Moscoso y Peralta, criollo visto con desapego por los peninsulares, acusado de haber propiciado la ocasión del levantar.iento de Túpac Amaru, al luchar en contra del corregidor de Tinta Antonio de Arriaga, decidió aprovechar este favorable momento paru reiterar su fidelidad a Carlos III. Su respuesta a Areche, escrita el 13-IV-1781, es un alegato criollo contra el Indio y las supervivencias iricaicas de su vida social. El prelado es de parecer que se recojan todas las pinturas de los Incas, tenidas en gran veneración. Señala que los Indios son supersticiosos y muy apegados a sus tradiciones, más impresionables por lo que ven que por lo cue oyen, mezclando groseras prácticas idolátricas con el rito cristiano. Hace una descripción de sus trajes, instrumentos y lenguaje, recalcando la persistencia de este último. Sus usos cotidianos, le permite calificar de idiomas vivos al Kechua, al Aymara y al Pukina, habla nativa que aconseja eliminar. Al referirse a los Comentarios Reales y al caudillo Túpac Amaru, literalmente dice: "Si los Comentarios de Garcilazo no huvieran sido toda la lectura é instruccion del Ynsurgente Josef Gabriel Tupa Amaro; si sus continuas invectivas, y declamaciones contra los españoles, no se huviesen radicado tanto en su animo; si lo que habla de lo Señores Virreyes que governaron los principios de este Reyno; de las Reales Audiencias, y demás tuezes, noese huviese permitido dar tan fácilmente á la prensa, y en una palabra, si estas, y otras lecciones de algunos Autores Regnicolas no hubieran tenido la aceptacion del Traydor en lo mucho que en ellas se vierte sobre la conquista no emprenderia Tupa Amaro el arrojo detestable de su revelion. Este se mantenia quieto en los confines del cortisimo Pueblo de Tungasuca, reducido á la labor de unos infertiles semtrados, y sujeto al aparejo, y reata, en el trafico de Mulas; pero la incauta expresion de muchos imprudentes, y manejo de aquellos libros que devian quemarse alentaron aquel espiritu para la irrupción que experimento el Reyno y de cuias resultas, no podria convalecer á no havernos deparado la Divina providencia un $\mathrm{He}$ roe tan cumplido con Vuestra Señoria que con su infatigable actividad, y feliz expediente, nos há redimido de la opresión presente, y vá á reparar sus lastimosas quiebras" "4. Y añade, que las 
Audiencias no tramiten expedientes sobre reconocimiento de ascendencia noble provenientes de los antiguos Incas y se prohiba la presencia de autoridades específicas para los Indios.

Este prolijo alegato del prelado fue reproducido como suyo por el visitador Areche ${ }^{5}$, en comunicación que envió al ministro de Indias José de Gálvez, desde el Cusco el l-V-1781. El Visitador sigue punto por punto lo alegado por el Obispo, como uno de los medios de pacificar definitivamente el Virreinato. Las noticias enviadas también al ministro Gálvez por el oidor Benito de la Matalinares, ratifican en lo fundamental los conceptos de Areche. Este debió pesar en la Corte, pues Matalinares estuvo encargado do sustanciar el proceso contra Túpac Amaru.

Con tales precedentes, Carlos III prohibió en sus dominios la circulación de los Comentarios Reales y mandó recoger sus ejemplares por Real Orden, dada en Aranjuez el 21-JV-1782. En su texto, la Corte expresa ser de urgente necesidad extirpar los abusos cometidos por los Indios del Perú y otros territorios de Ultramar, extralimitación alimentada por el apego a sus costumbres $y$, especialmente, por derechos irrogados de algunas personas con calificación oficial de nobleza autóctona. En consecuencia, manda el Rey a las Audiencias -por vía reservada- detener todo trámite a los expedientes sobre reconocimiento de nobleza indígena, trámite que desde entonces correspondería exclusivamente al Consejo délindiasecy ordeñépora todos los medios recoger los ejemplares de la "Historig" (Comentarios Reales) escrita por Garcilaso Chimpuocllo, obra considerada como perjudicial y contraria a la incondicional sumisión del poblador indígena, así como también de todo papel impreso que expresase ideas lesivas a la autoridad real.

Como complemento, se inserta una fotocopia de la Real Orden prohibiendo la circulación de los Comentarios -en tres páginas-, documento perteneciente al Archivo del suscrito.

5 Ibid. 
Reserumaa

$t$

Son muctur tos almoss ve ofua estar foretiorir en ito common los Ynous we ere Reyno weil Dexue, or Demses Parmí

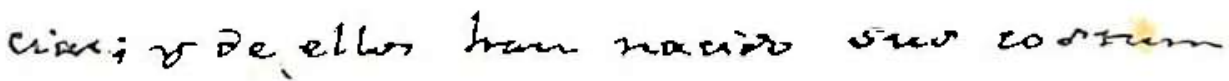

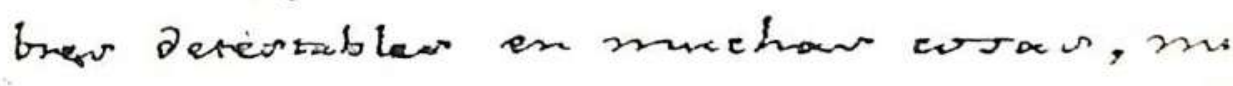

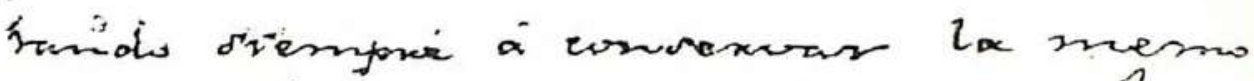

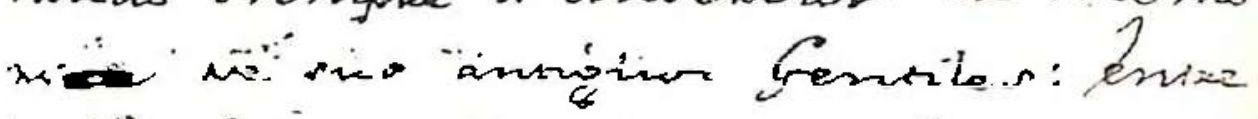

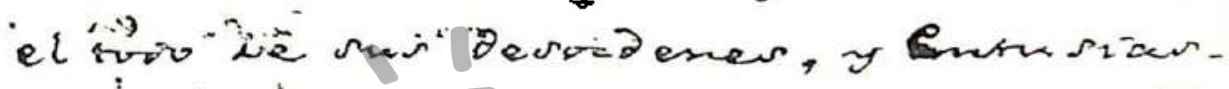

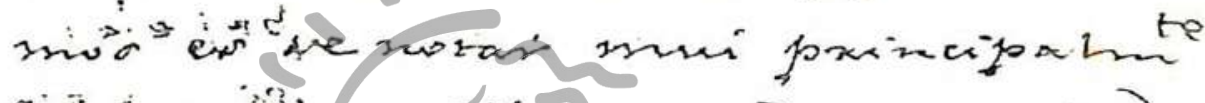

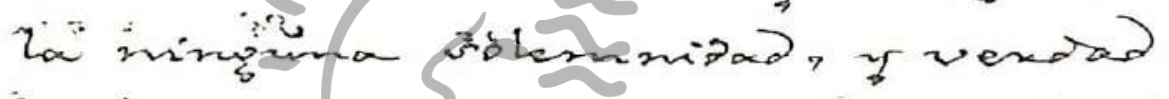

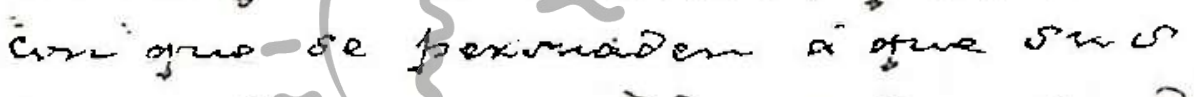

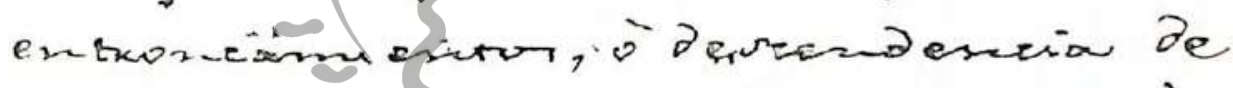

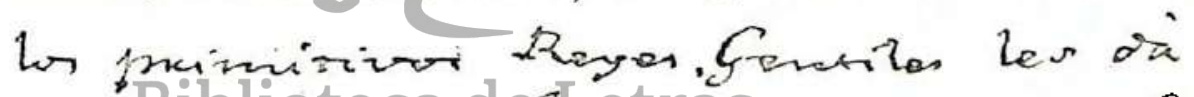

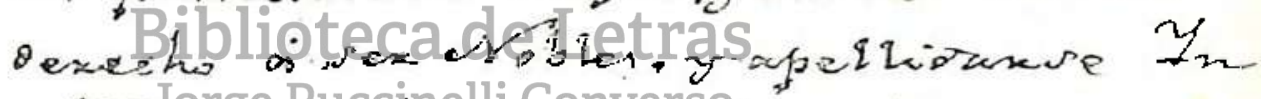
ourge Pucginelli Converso" se ha viswo con

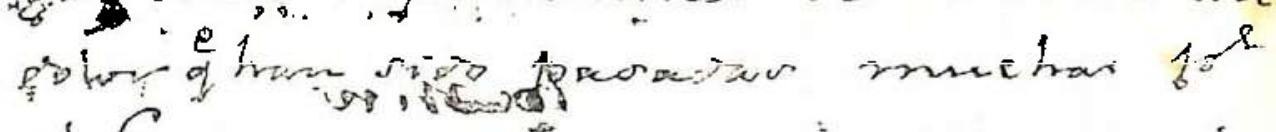

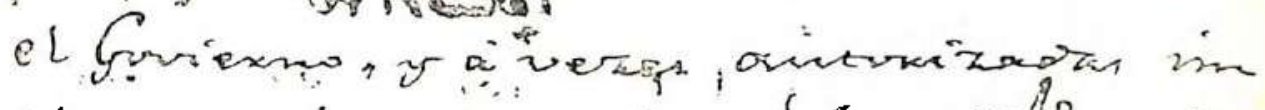

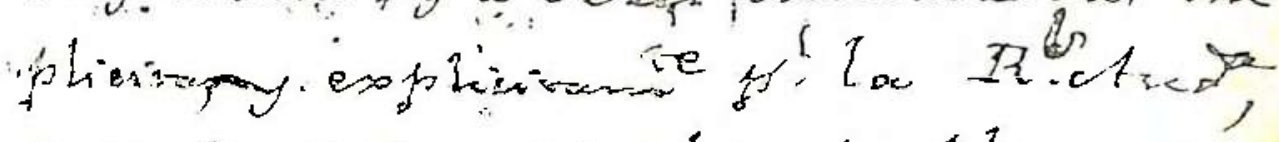

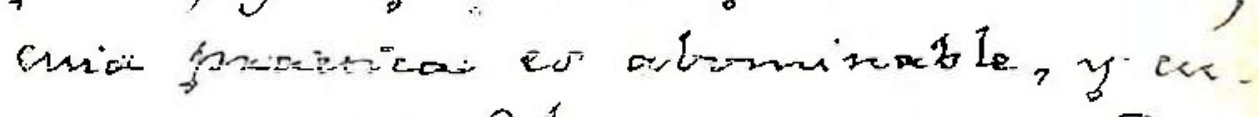

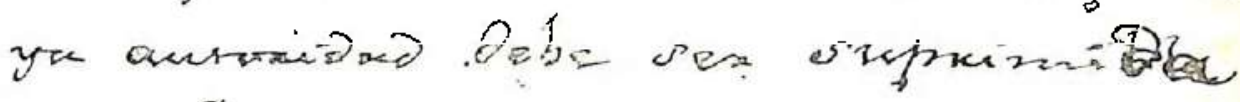

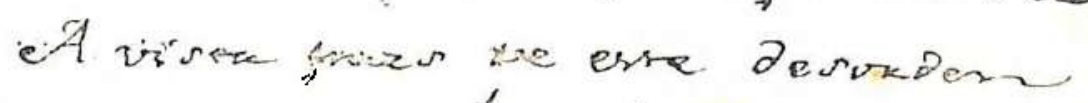

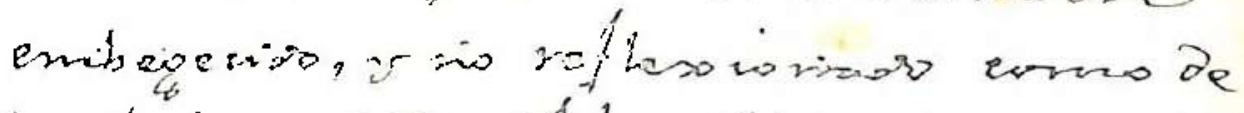

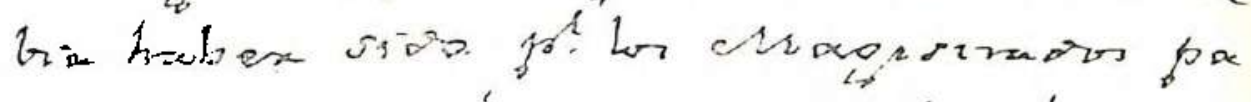

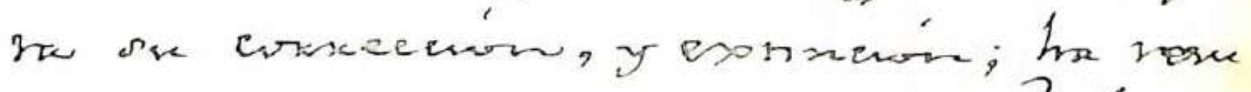

7 elto 


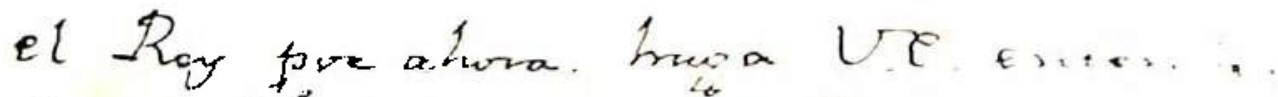
a'espe R'ctupientio we Lima wr-

A para semafor te colfticacion

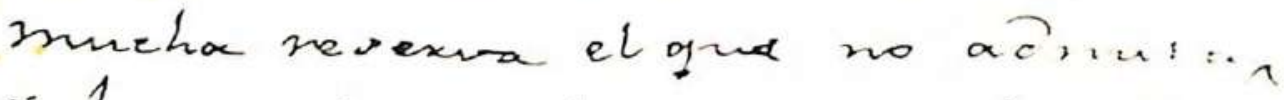
infurmaciones aloumas ve iales exstin.

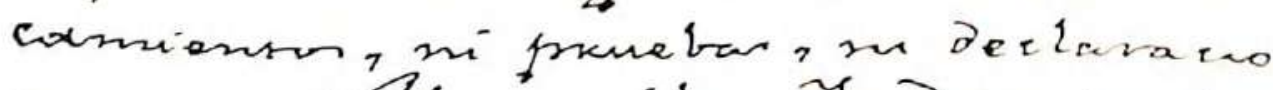

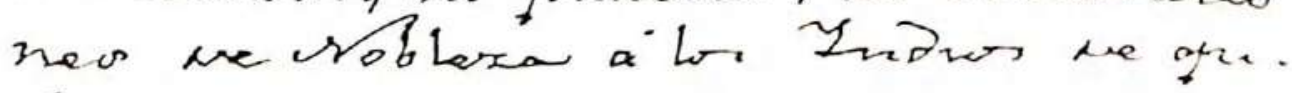

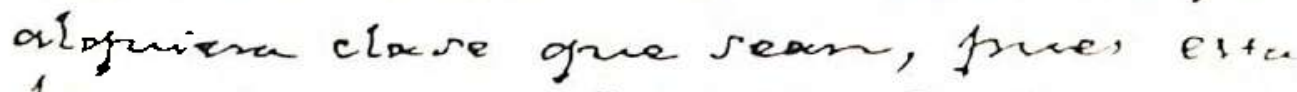

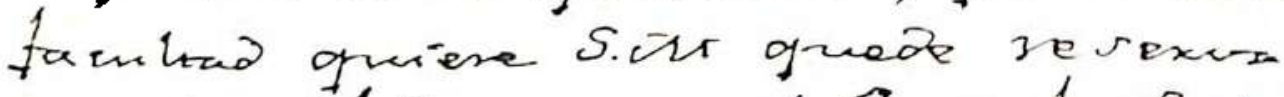

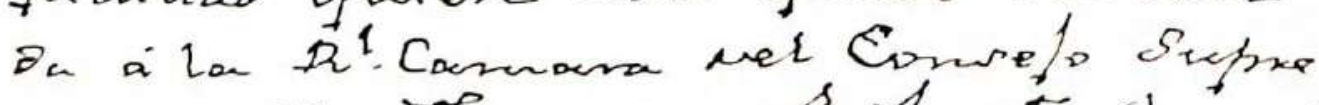

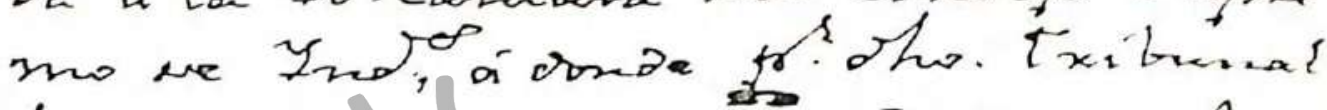

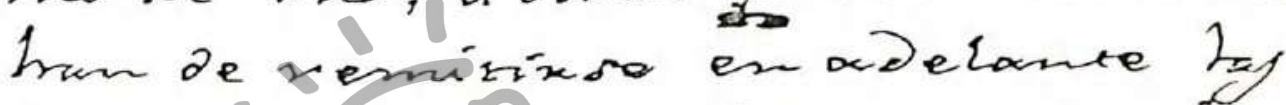

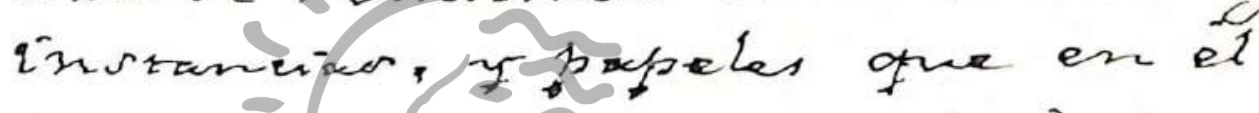
seprevestes, Sin neperitad he

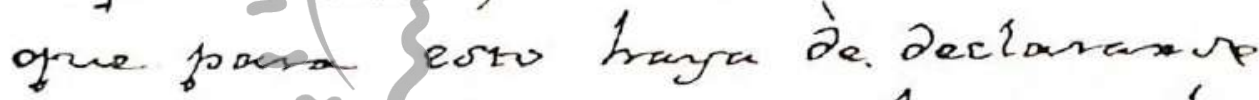
erra, revolucuin we S.cu. Hasta el.

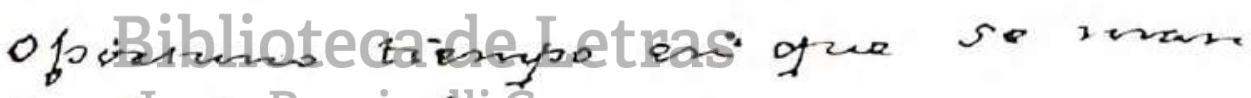
a arworge Pupcinelli Egnerse"e.

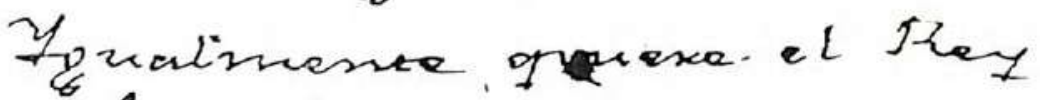

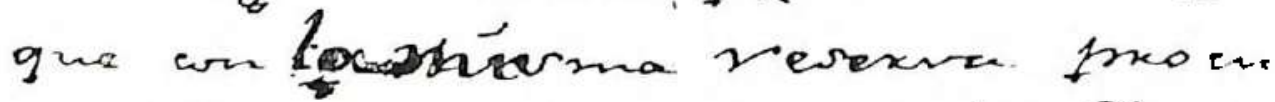
ke Ve rewoer sagwaneme lo Jtisto

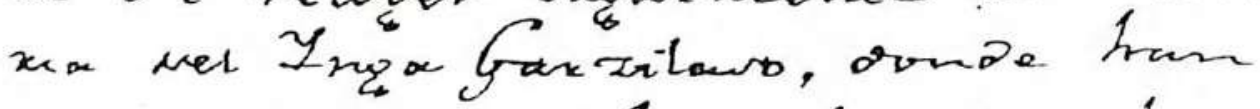

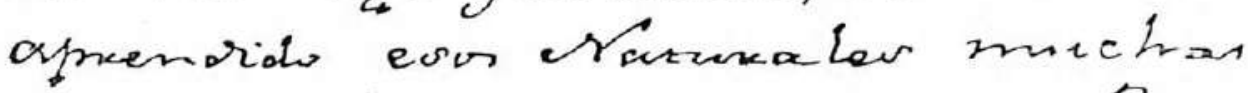

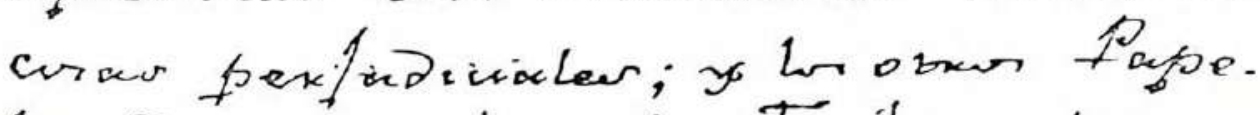
Les Detxactorenis we hos Txibmuales, y

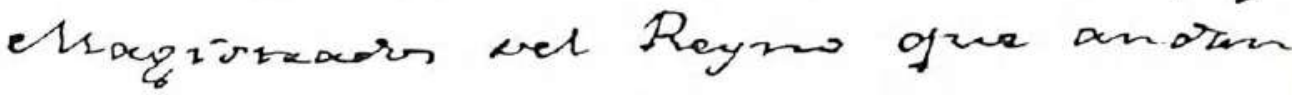
impicesor de un tiempo en of ue de

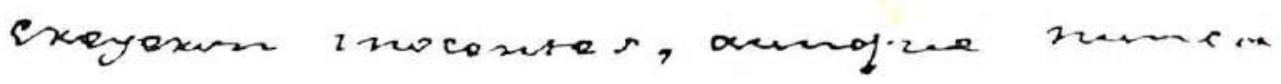


Detwo poxmitixe lo proofecia supros

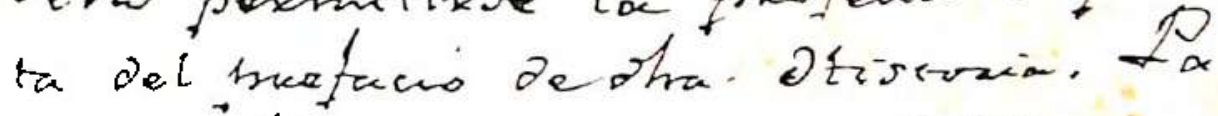

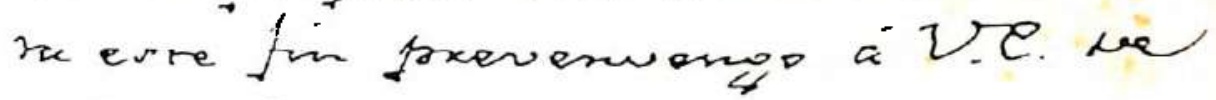

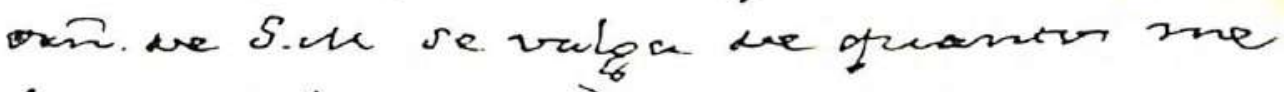
oros revulare conpusemes, arenofue Sea tracienos curmprars Wr esoerughar res we estas obxar pox texcesar Pex.

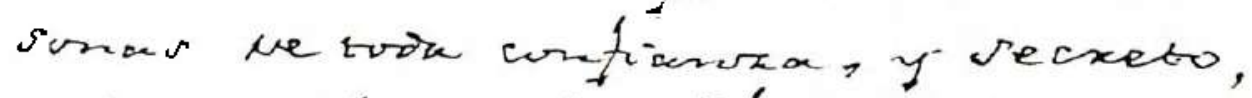

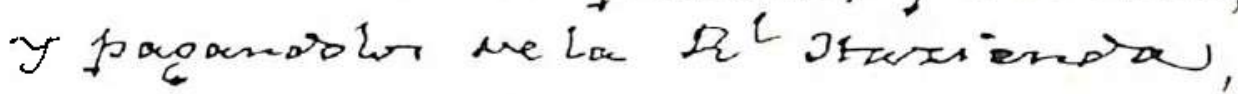
phes tantolimpsorea el of we lleace

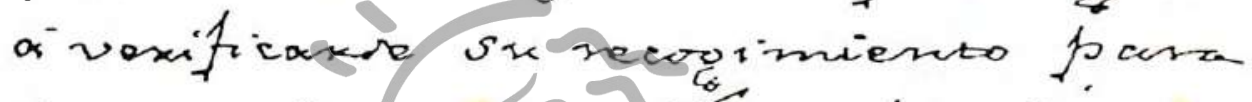

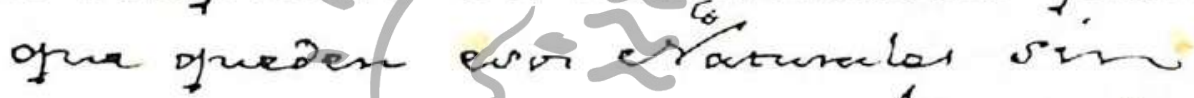
erte morivo mber the vivificas sur

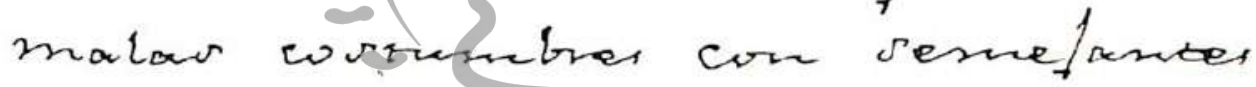

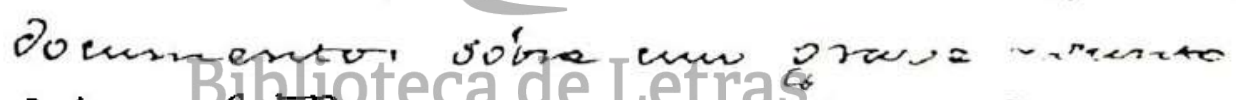

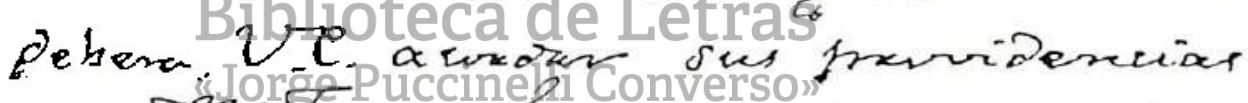

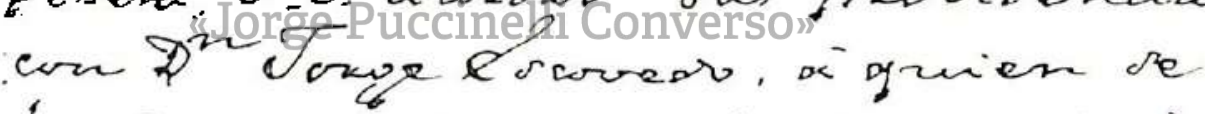
le alviexce lo froughio forra sul

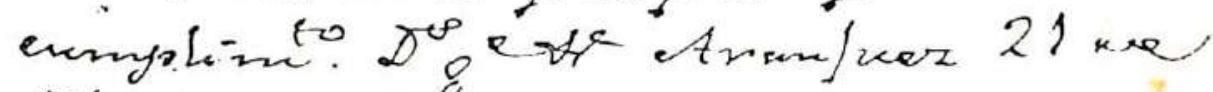

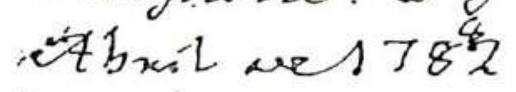

8. irkinay aril sexin

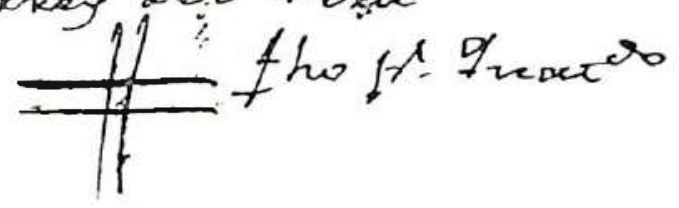

